\title{
DEVELOPMENT AND VALIDATION FOR FREE AGLYCONES DAIDZEIN AND GENISTEIN IN SOYBEANS (GLYCINE MAX (L.) MERR.) USING RP HPLC METHOD
}

\author{
ETTY SULISTYOWATI ${ }^{1,2}$, SUDIBYO MARTONO ${ }^{2}$, SUGENG RIYANTO2 ${ }^{2}$, ENDANG LUKITANINGSIH ${ }^{2 *}$
}

${ }^{1}$ Pharmaceutical Studie Program, College of Pharmaceutical Science Yayasan Pharmasi Semarang, Semarang 50192 Indonesia, ${ }^{2}$ Faculty of Pharmacy Gadjah Mada University, Yogyakarta 55281 Indonesia

Email: lukitaningsih_end@ugm.ac.id

Received: 03 Dec 2018, Revised and Accepted: 30 Jan 2019

\section{ABSTRACT}

Objective: The aim of this research was to develop a validation method for free aglycones analysis especially daidzein and genistein in soybean (Glycine max (L.) Merr.) using High Performance Liquid Chromatography (HPLC).

Methods: In this study, reversed-phase HPLC (RP-HPLC) equipped with an endcapped Sun Fire TM C-18 column (150 mm x $4.6 \mathrm{~mm}, 5 \mu \mathrm{m})$ was used for the separation. The binary mobile phase consisted of methanol and $0.1 \%$ acetid acid (53:47). An isocratic program was used with a flow rate at $1.0 \mathrm{ml} / \mathrm{min}$ and the injection volume was $10 \mu \mathrm{l}$. The analytes were detected by using Photo-diode array (PDA) at $254 \mathrm{~nm}$ and the samples in various soybean varieties from Balitkabi Malang, Indonesia.

Results: The developed method showed that the parameters of system suitability and selectivity meet the requirements of method validation. The accuracy values of recoveries for daidzein $83.0 \%-100.95 \%$ and genistein $80.07 \%-108.79 \%$, and the precision was calculated $\%$ RSD $\leq 2 \%$ respectively, linearity of the method was the r2values ranged from 0,9989-0,9991 and all the parameters meet the acceptable criteria of validated method. The Limit of detection (LoD) and Limit of quantitation (LoQ) indicated a good sensitive method, with LoDs values obtained, were 0.05192 $\mu \mathrm{g} / \mathrm{ml}$ and $0,0600 \mu \mathrm{g} / \mathrm{ml}$ for daidzein and genistein, respectively. Meanwhile, the LoQs values was $0.1731 \mu \mathrm{g} / \mathrm{ml}$ and $0.2000 \mu \mathrm{g} / \mathrm{ml}$ for daidzein and genistein, respectively.

Conclusion: A simple, accurate, precise and being specific HPLC method coupled to PDA for the analysis of daidzein and genistein in various soybeans varieties were developed and validated.

Keywords: Daidzein, Genistein, Free aglycones, HPLC, Soybean varieties

(c) 2019 The Authors. Published by Innovare Academic Sciences Pvt Ltd. This is an open access article under the CC BY license (http://creativecommons.org/licenses/by/4.0/) DOI: http://dx.doi.org/10.22159/ijap.2019v11i2.31222

\section{INTRODUCTION}

Soybean (Glycine max (L.) Merr) is one of the essential food sources consumed by many Asian people including Indonesia. Isoflavones (plant secondary metabolites of the family flavonoids) are present in high concentrations in soybean and soy products [1]. The content of isoflavones in soybean will play important role in nutrients value of soybean. Therefore, the farmers will cultivate and plant soybean varieties containing a high concentration of isoflavones. Isoflavones have estrogenic effects, genistein is able to prevent osteoporosis [2]. Daidzein and genistein at doses of $0.2-20 \mu \mathrm{M}$ were able to inhibit ovarian endometrioma cell proliferation in endometriosis in mice [3]. Soybeans are one of the biggest sources of isoflavones compared to nuts and meat products [4], and the best sources of isoflavones are in soybeans. Isoflavone can be found both forms, aglycone and glycoside form. However, an isoflavone in aglycone form such as daidzein and genistein, is the more effective than glycoside form, because it has good biological activity and also easily to be absorbed [5].

Isoflavones in soybeans consisted of malonil-glycosides, acetylglycosides, glycosides, and aglycones. Among the four forms of isoflavones, the highest biological activity is shown by aglycone isoflavones, especially genistein (5,7,4'-trihydroxy isoflavone), daidzein (7,4'-dihydroxy isoflavone) and glyciteine (6-methoxy-7,4'-dihydroxy isoflavone) [6]. Genistein and daidzein can prevent osteoponia in postmenopausal women [7]. In the field of food, daidzein enriched animal feed was able to improve the quality of beef [8]. However, soybean types, geographical locations, and processing methods have a major influence on the active substance content in soybeans [9].

Several analytical methods have been used for analysis of daidzein and genistein, namely high-performance liquid chromatography (HPLC) [10-12], Raman spectroscopy [13], FTIR spectroscopy and [14] polarimetry [15]. The most widely used analytical technique is reversed phase HPLC using C18 column with the mobile phase of acetonitrile, methanol $[10,11,16]$. Analysis of daidzein and genistein in soybeans requires a more efficient, accurate method and simple sample preparation. A lot of research used gradient elution systems [10, 16-19], but this method can be optimized by the isocratic system [11]. For this reason, this research was intended to develop an analytical method using HPLC for the analysis free aglycones, especially daidzein and genistein in various soybean varieties.

\section{MATERIALS AND METHODS}

\section{Materials}

The standard chemicals of daidzein and genistein were purchased from Sigma (Aldrich, USA). The HPLC grade solvents, water for chromatography (LC-MS grade), metanol and acetonitrile chromatography grade were obtained from E. Merck KgaA (Darmstadt, Germany), metanol pro analysis (analytical reagent grade) and acetic acid were also bought from Merck KgaA (Darmstadt, Germany). Soybean with various varieties was obtained from Indonesian Legumes and Tuber Crops Research Institute (Balitkabi), jalan raya Kendal Payak Km 8 Malang 65162, Indonesia.

\section{Preparation of working solution}

Quantitative analysis of daidzein and genistein standard was performed by weighing an approximately of $1.0 \mathrm{~g}$ sample accurately and then dissolved with mobile phase. The solution was filtered using $0.45 \mu \mathrm{m}$ membranfilter. The working solutions containing concentrations of daidzein and genistein were prepared by dilution using mobile phase, and $20 \mu \mathrm{l}$ of the filtered solution was injected in HPLC system.

\section{HPLC instrumentation}

All solutions of samples were subjected to RP-HPLC measurement using the condition as follows: column of Sun Fire TM C-18 $(150 \mathrm{~mm}$ $\mathrm{x} 4.6 \mathrm{~mm}, 5 \mu \mathrm{m}$ ), the mobile phase a mixture of methanol and $0.1 \%$ acetid acid (53:47) and delivered isocratically with flow rate at 1.0 
$\mathrm{ml} / \mathrm{min}$. The analytes were detected by using Photodiode array (PDA) at $254 \mathrm{~nm}$.

\section{Validation of the analytical method}

Validation of the established method was performed based on parameters as suggested by ICH guideline [20]. The procedure was validated in terms of specificity, precision, accuracy, linearity, and sensitivity.

\section{Specificity}

Method specificity is the ability of an analytical method to measure the intended analyte precisely and specifically in the presence of other components in the sample. The intended compounds are determined by calculating their separation or resolution (Rs) from other compounds.

\section{Precision}

The intraprecision was determined by instrumental precision in both intraday precision (repeatability) and interday precision (intermediate precision). Precision was expressed in terms of calculated as relative standard deviation (RSD in percent). The intraday precision was evaluated by analysing six samples during the same day. Precision is measured as relative standard deviation. This is done by making 6 replication samples at $\mu \mathrm{g} / \mathrm{ml}$ and injecting them into the HPLC system.

\section{Accuracy}

The accuracy of the method was determined by application of the standard addition method. Three Levels of concentrations for daidzein and genistein were added into the sample and analyzed in triplicate as describe above. The total amount of each compound was calculated from the corresponding calibration plot and the percentage recovery of the each compound was calculated.

\section{Linearity}

For the linearity test, a standard solution containing daidzein and genistein $(100 \mu \mathrm{g} / \mathrm{ml})$ was prepared. Aliquots of the solution $(2,3,4$, $5,6,7,8,9$ dan $10 \mu \mathrm{g} / \mathrm{ml}$ ) were injected into the HPLC equipment. The linear regression equation and correlation coefficients were calculated for each daidzein and genistein using Microsoft Exel $^{\circledR}$ (Microsoft Corp., USA). Linearity is a measure of the ability of the analytical method to relate the response to the levels of analytes on the calibration curve to form a straight line.

\section{Sensitivity}

The sensitivity of the analytical method was expressed by the limit of detection (LoD) and the limit of Quantification Limit (LoQ). For determination of LoD and LoQ, diluted standard solutions were injected into the HPLC equipment, at decreasing concentrations (1.4$0.4 \mu \mathrm{g} / \mathrm{ml}$ ). LoD was defined as the concentration for which a signal to noise ratio of 3:1 was obtained, while LoQ was determined based on the signal to noise ratio of 10:1.

\section{Quantitative analysis of daidzein and gensitein in soybean}

Approximately of $2.5 \mathrm{~g}$ sample was massed into $100 \mathrm{ml}$ amber vials and added with $25 \mathrm{ml}$ methanol $50 \%$ for maceration. Finally, the supernatants were filtered through $0.45 \mu \mathrm{m}$ syringe filter (PVDF Acrodisc LC) and transferred into a glass vial for HPLC analysis. Daidzein and genistein concentrations were calculated as $\mathrm{mg}$ of isoflavones per $100 \mathrm{~g}$ of soybean.

\section{RESULTS AND DISCUSSION \\ HPLC condition optimization}

Quantitative analysis of daidzein and genistein was performed by HPLC using PDA detector. The PDA detector is able to provide a collection of chromatograms simultaneously at different wavelengths in one running. Using PDA detector, UV spectra from $200-400 \mathrm{~nm}$ were online recorded for peak identification. The PDA detection was performed at $254 \mathrm{~nm}$, The injection volume was $20 \mu$ l. Optimization of mobile phase composition and flow rate used for analysis affected the retention time (Rt) and resolution. The chromatographic parameters were initially evaluated for a standard solution of daidzein and genistein $(5 \mu \mathrm{g} / \mathrm{ml})$. Resolution, tailing factor and $\mathrm{N}$ plate were determined for different proportions of acetonitrile or methanol and the aqueous solvents. Different proportions of this solvents were evaluated and the results showed that acetonitrile and water as the mobile phase give unfavorable resolution results. The mobile phase of methanol-water has shown a good resolution for two compounds of daidzein and genistein. The separation of aglycones was evaluated in different mobile phase compositions. The mobile phase obtained from the optimization was a mixture of methanol: $0.1 \%$ acetid acid (53:47) with a flow rate of $1.0 \mathrm{ml} / \mathrm{min}$. Isabela et al. [11] also used with similar mixture of the mobile phase, but with a different composition. The RSD values for peak area and peak height obtained meets the requirements of maximum RSD $\leq 2 \%$ [21]. The chromatogram of soybean samples containing-daidzein and genistein were shown in fig. 1, 2 and 3.

\section{System suitability test (SST)}

System suitability test was carried out by injecting daidzein and genistein standard solutions at a concentration of $5 \mu \mathrm{g} / \mathrm{ml}$ with sixtime replicates. The results obtained showed that the conditions used for the determination of the levels of daidzein and genistein in the sample had good system suitability based on retention time, peak area and peak height requirements, $\%$ RSD $\leq 2 \%$ [24] for the analysis of daidzein and genistein, The values of SST in table 1.

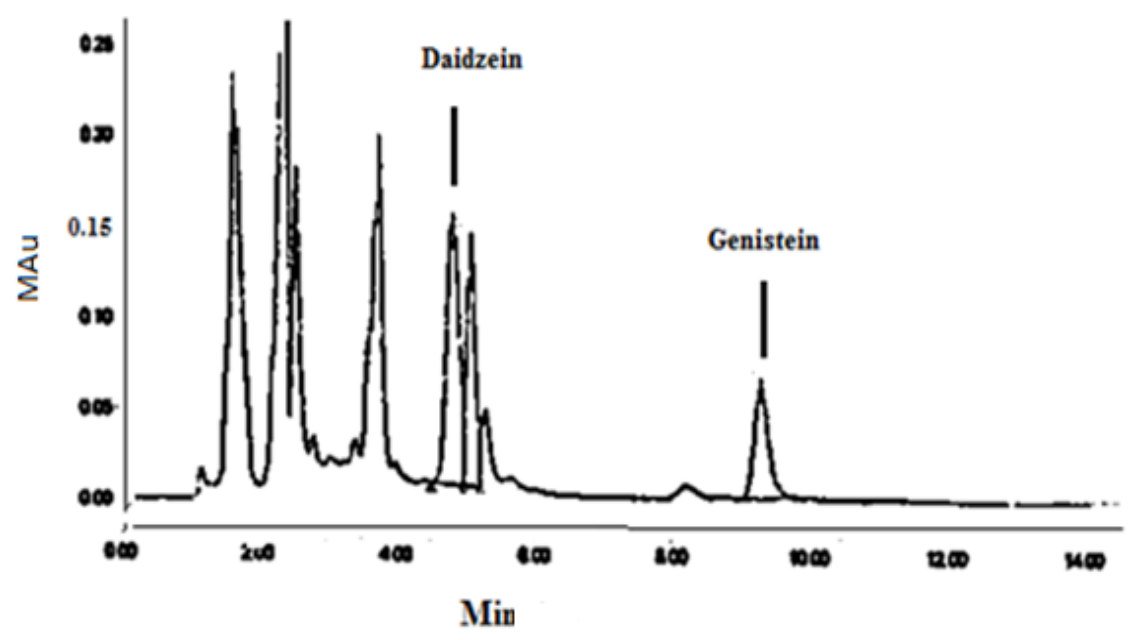

Fig. 1: Chromatogram of soybean samples obtained by HPLC using sun fire TMC-18 C18 coloumn (150 mm x $4.6 \mathrm{~mm}, 5 \mu \mathrm{m})$. The mobile phase used was acetoniril: $0.1 \%$ acetic acid (35: 65), flow rate of $0.8 \mathrm{ml} / \mathrm{min}$ 


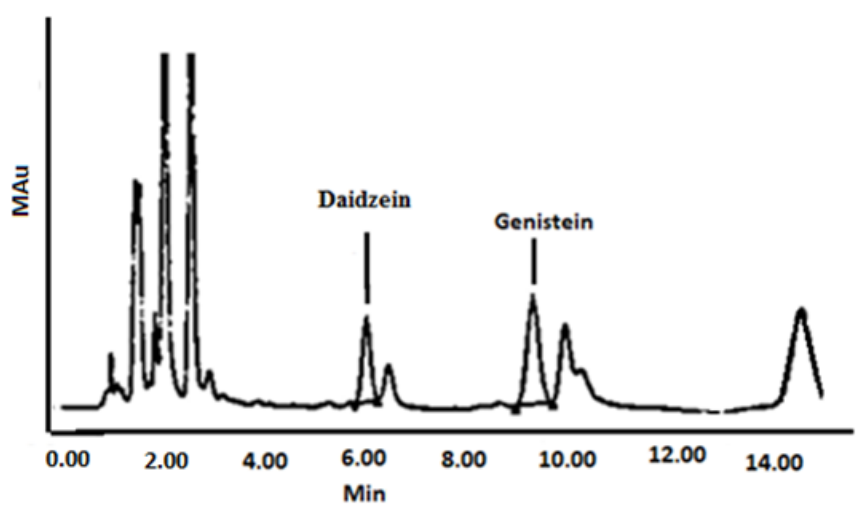

Fig. 2: Chromatogram of soybean samples obtained by HPLC with the Sun Fire TMC-18 C18 coloumn (150 mm x $4.6 \mathrm{~mm}, 5 \mu \mathrm{m})$. The mobile phase used was methanol: $0.1 \%$ acetic acid (53:47), flow rate of $1.0 \mathrm{ml} / \mathrm{min}$

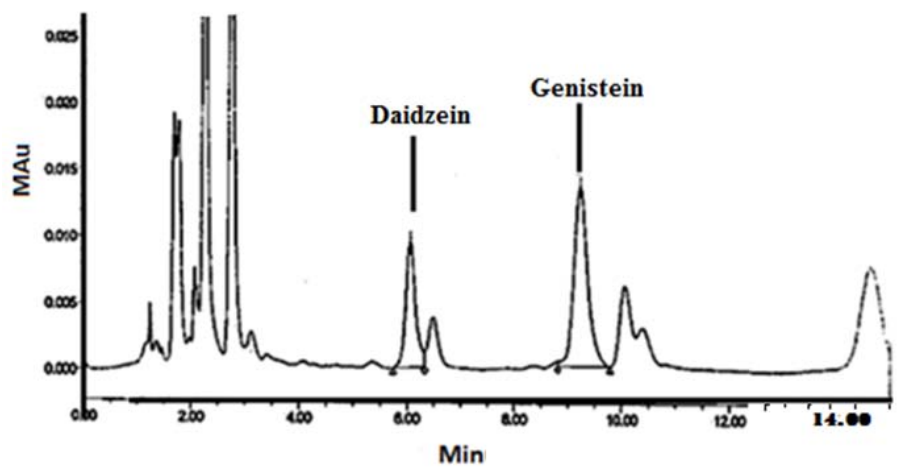

Fig. 3: Chromatogram of the sample obtained by HPLC with Sun Fire TMC-18 C18 coloumn (150 mm x $4.6 \mathrm{~mm}, 5 \mu \mathrm{m})$. The mobile phase of methanol: $0.1 \%$ acetic acid (53:47), flow rate of $1.0 \mathrm{ml} / \mathrm{min}$. Spiking was performed with $1 \mathrm{ppm}$ of daidzein and genistein, respectively

Table 1: System suitability obtained for analysis of daidzein and genistein using HPLC with optimum condition

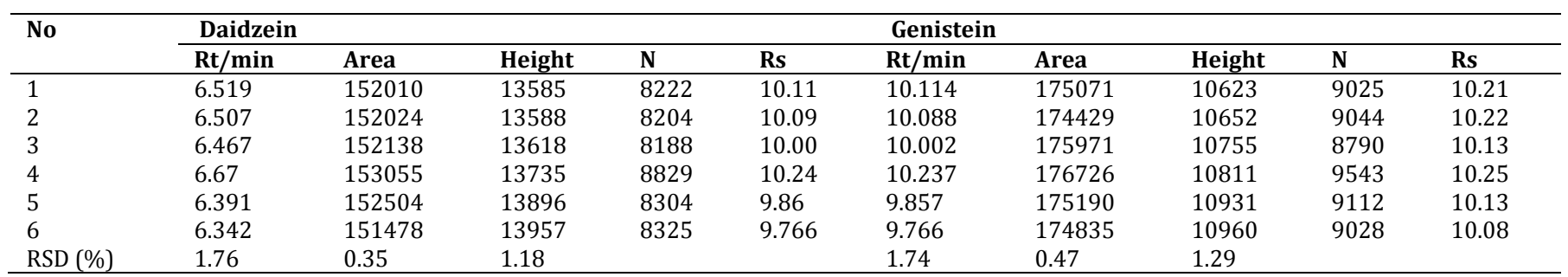

The accuracy of the method was investigated by means of recovery experiment with the addition standard of three-level was expressed calculated as the concentration recovery percentage. A mean recovery $(n=9)$ of concentration obtained for daidzein $83.0 \%$ $100.95 \%$ and genistein $80.07 \%-108.79 \%$. The acceptable value of recovery for biological compound analysis was $80-115 \%$ [23]. The precision of HPLC was evaluated by repeatability and intermediate precision at different days of analysis. The relative standard deviation (RSD) values were used for precision evaluation. In the intra-day precision analysis $(n=6)$, the mean contents of daidzein was level $1=0.33 ; 1.00 ; 0.67$, level $2=0.99 ; 0.67 ; 1.24$ and level $3=$ $0.29 ; 1.41 ; 0.32$. For genistein was level $1=1.29 ; 1.11$; and 1.43 , level $2=1.29 ; 0.28 ; 1.43$ and level $3=0.35 ; 0.70 ; 1.99$. The obtained $\%$ RSD was less than $6.00 \%$, so that the precision of the proposed method meet the required value as described in method validation guideline. [23].

Linearity is a measure of the ability of the analytical method to correlate the response with the analyte levels on the calibration curve to form a straight line. Linearity is also the ability of a method to obtain a test result that is directly proportional to the concentration of analytes in the given range. The linear regressions obtained were shown in fig. 4. Linear calibrations were obtained for daidzein and genistein with the correlation of determination in the range of $0,9989-0,9991$ for calibrations, linearity is achieved when the coefficient of determination $\left(\mathrm{r}^{2}\right)$ is $\geq 0.997$ [24].

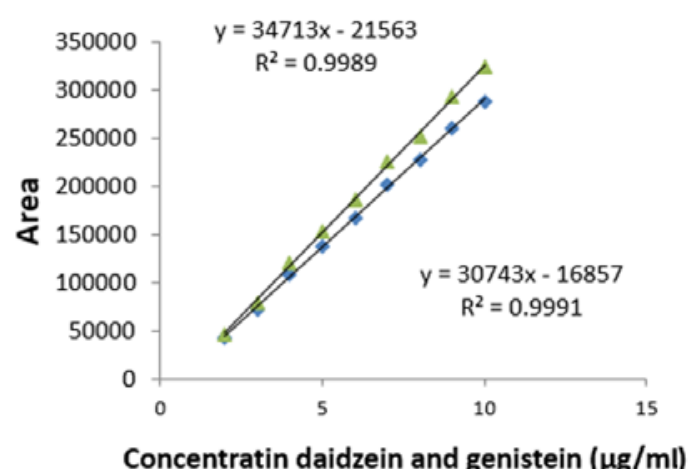

Fig. 4: The relationship between the concentration of daidzein and genistein ( $x$-axis) and peak area $(y$-axis) 
The sensitivity of the analytical method was expressed by the limit of detection (LoD) and limit of quantitation. LoD values obtained were of $0.05192 \mu \mathrm{g} / \mathrm{ml}$ and $0.0600 \mu \mathrm{g} / \mathrm{ml}$ for daidzein and genistein, respectively. Meanwhile, LoQ values obtained were $0.1731 \mu \mathrm{g} / \mathrm{ml}$ and $0.2000 \mu \mathrm{g} / \mathrm{ml}$ for daidzein and genistein, respectively. Based on validation parameters evaluated, it can be concluded that the HPLC method was valid for the quantitative analysis of daidzein and genistein in soybean samples. The validated HPLC method was used for analysis of soybean samples, and the results were compiled in table 2 .

Table 2: The contents of daidzein and genistein in several cultivars of soybean

\begin{tabular}{llll}
\hline No & Soybean cultivars & Daidzein (mg/100 g) & Genistein (mg/100g) \\
\hline 1 & Burangrang & $20.32 \pm 0.39^{*}$ & $15.07 \pm 0,66^{*}$ \\
2 & Dieng & $24.12 \pm 1.48^{*}$ & $15.38 \pm 1.73^{*}$ \\
3 & Demas & $29.40 \pm 0.99^{* *}$ & $23.65 \pm 2.30^{* *}$ \\
4 & Devon 1 & $19.11 \pm 0.30^{*}$ & $17.04 \pm 0.34^{*}$ \\
5 & Dega & $13.75 \pm 0.43^{* *}$ & $12.82 \pm 1.07^{* *}$ \\
6 & Detam 1 & $10.49 \pm 0.26^{*}$ & $12.49 \pm 1.01^{*}$ \\
7 & Gema & $11.06 \pm 0.41^{*}$ & $15.76 \pm 1.03^{*}$ \\
8 & Gepak Kuning & $18.00 \pm 0.37^{* *}$ & $17.29 \pm 1.07^{* *}$ \\
9 & Gumintir & $26.39 \pm 1.74^{*}$ & $23.29 \pm 1.03^{* *}$ \\
10 & Kawi & $15.38 \pm 0.42^{* *}$ & $16.19 \pm 1.16^{* *}$ \\
11 & Malika & $18.17 \pm 0.82^{* *}$ & $17.33 \pm 0.67^{* *}$ \\
12 & Merbabu & $42.65 \pm 0.87^{*}$ & $33.32 \pm 1.03^{*}$ \\
13 & Mahameru & $18.11 \pm 0.67^{*}$ & $15.09 \pm 0.40^{*}$ \\
14 & Rajabasa & $26.32 \pm 0.99^{*}$ & $22.43 \pm 5.76^{*}$ \\
15 & Rinjani & $22.49 \pm 0.39^{*}$ & $19.71 \pm 1.72^{*}$ \\
16 & Roung & $26.92 \pm 2.08^{* *}$ & $24.50 \pm 1.25^{* *}$ \\
\hline
\end{tabular}

The results for daidzein and genistein contents in several cultivars of soybean in replication $n=5\left(^{*}\right)$ and $n=6\left(^{* *}\right)$

\section{CONCLUSION}

HPLC method using reversed phase mode offered reliable and validated techniques for the quantification of isoflavones free aglycones (daidzein and genistein) in soybean samples. The developed method is a simple method and could be applied for routine quality control of daidzein and genistein in various of soybeans varieties.

\section{ACKNOWLEDGMENT}

The authors thank to Faculty of Pharmacy for financial support and to Prof. Abdul Rohman from Faculty of Pharmacy Gadjah Mada University Yogyakarta, also to Eriyanto Yusnawan Ph. D from Balitkabi Malang for support this research.

\section{AUTHORS CONTRIBUTIONS}

ES-performed research activities and prepared manuscript. EL,-, SM, and SR designed research analyzed data and made critical thinking on a manuscript.

\section{CONFLICTS OF INTERESTS}

All authors have none to declare

\section{REFERENCES}

1. Kuhnle G, Dell'Aquila C, Aspinall S, Runswick S, Mulligan A, Bingham S. Phytoestrogen content of foods of animal origin: dairy products, eggs, meat, fish, and seafood. J Agric Food Chem 2008;56:10099-104.

2. Morabito N, Morabito N, Crisafulli A, Vergara C, Gaudio A, Lasco A, et al. Effects of genistein and hormone-replacement therapy on bone loss in early postmenopausal women: a randomized double-blind placebo-controlled study. J Bone Miner Res 2002;17:1904-12.

3. Takaoka $\mathrm{O}$, Mori $\mathrm{T}$, Ito F, Okimura $\mathrm{H}$, Kataoka H, Tanaka Y, et al. Daidzein-rich isoflavone aglycones inhibit cell growth and inflammation in endometriosis. I Steroid Biochem 2018; 181:125-32.

4. Thompson LU, Boucher BA, Liu Z, Cotterchio M, Kreiger N. Phytoestrogen content of foods consumed in Canada, including isoflavones, lignans, and coumestan. Nutr Cancer 2006;54:184-201.

5. Izumi T, Piskula M, Osawa S, Obata A, Tobe K, Saito M, et al. Soy isoflavone aglycones are absorbed faster and in higher amounts than their glucosides in humans. J Nutr 2000;130:1695-9.

6. Gu L, Gu W. Characterisation od soy isoflavones and screening for novel malonyl glycosides using high-performance liquid chromatography-electrospray ionization mass spectrometry. Phytochem Anal 2001;12:377-82.

7. Islam F, Sparkes C, Roodenrys S, Astheimer L. Short-term changes in endogenous estrogen levels and consumption of soy isoflavones affect working and verbal memory in young adult females. Nutr Neurosci 2008;11:251-62.

8. Zhao XH, Zhao X, Yang Z, Bao L, Wang C, Zhou S, et al. Daidzein enhances intramuscular fat deposition and improves meat quality in finishing steers. Exp Biol Med 2014;240:1152-7.

9. Hong JH, Qin X, Shu P, Wang Q, Zhou Z, Lin B, et al. Comparative study of isoflavones in wild and cultivated soybeans as well as bean products by high-performance liquid chromatography coupled with mass spectrometry and chemometric techniques. Eur Food Res Technol 2011;233:869-80.

10. Shao SA, Duncan M, Yang R, Marcone MF, Rajcan I, Tsao R. Systematic evaluation of pre-HPLC sample processing methods on total and individual isoflavones in soybeans and soy products. Food Res Int 2011;44:2425-34.

11. da Costa Cesar I, Braga F, Soares C, de Aguiar Nunan E, Pianetti G, Condessa F, et al. Development and validation of an RP-HPLC method for quantification of isoflavone aglycones in hydrolyzed soy dry extracts. J Chromatogr B: Anal Technol Biomed Life Sci 2006;836:74-8.

12. Alves R, Almeida I, Casal S, Oliveira M. Method development and validation for isoflavones quantification in coffee. Food Chem 2010;122:914-9.

13. Sekine R, Robertson EG, Mc Naughton D. Raman, infrared and computational analysis of genistein and its methoxy derivatives. Vib Spectrosc 2011;57:306-14.

14. Mulsow K, Eidenschink J, MF Melzig MF. FT-IR method for the quantification of isoflavonol glycosides in nutritional supplements of soy (Glycine max (L.) Merr.). Sci Pharma 2015;83:377-86.

15. Chang CC, Yang MH, Wen HM, Chern JC. Estimation of total flavonoid content in propolis by two complementary colometric methods. J Food Drug Anal 2002;89:178-82.

16. Luthria DL, Biswas R, Natarajan S. Comparison of extraction solvents and techniques used for the assay of isoflavones from soybean. Food Chem 2007;105:325-33. 
17. Yatsu FKJ, Koester LS, Bassani VL. An isoflavone-aglycone fraction from glycine max: a promising raw material for isoflavone-based pharmaceutical or nutraceutical products. Brazilian J Pharmacogn 2016;26:259-67.

18. Shim YS, Yoon WJ, J Hwang B, Park HJ, Seo D, Ha J. Rapid method for the determination of 14 isoflavones in food using UHPLC coupled to photodiode array detection. Food Chem 2015;187:391-7.

19. Redruello B, Guadamuro L, Cuesta I, Alvarez-Buylla JR, Mayo B, Delgado S. A novel UHPLC method for the rapid and simultaneous determination of daidzein, genistein and equol in human urine. J Chromatogr B 2015;1005:1-8.
20. ICH Topic Q2 (R1) Validation of Analytical Procedures: Text and Methodology. Int Conf Harmon; 2005.

21. Ermer J, Miller JHM. Method validation in pharmaceutical analysis: a guide to best practice; 2005.

22. Dolan JW, Snyder LR. Method development in liquid chromatography, in liquid chromatography. Fundamentals and Instrumentation; 2013. p. 386-98.

23. AOAC International. Guidelines for single laboratory validation of chemical methods for dietary supplements and botanicals. AOAC Int; 2002. p. 4-44.

24. Ahuja S, Dong MW. Handbook of pharmaceutical analysis by HPLC. Vol 6. Separation Science and Technology 1st edition, Elsevier Academic Press: San Diego; 2005. p. 197-203, 338. 